\title{
DEVELOPMENT OF PAVEMENT MANAGEMENT STRATEGIES FOR
}

\section{ARTERIAL ROADS}

\author{
Vishwanath G' ${ }^{1}$ Mahdev $^{2}$, M. R. Archana ${ }^{3}$, Krishna Prapoorna Biligiri ${ }^{4}$ \\ ${ }^{1,2}$ M.Tech IV semester, Highway Technology, ${ }^{3}$ Assistant Professor, Department of Civil Engineering, R. V. College of \\ Engineering, Bangalore-560059, India \\ ${ }^{4}$ Senior Research Scientist, Center for infrastructure, Sustainable Transportation and Urban Planning, Indian Institute of \\ Science, Bangalore, India: \\ vishwanathg055@gmail.com,swamy.dhaana@gmail.com,archanamr@rvce.edu.in,krishna@cistup.iisc.ernet.in
}

\begin{abstract}
An arterial road is a high-capacity urban road which delivers the traffic from collector roads to freeways, and between city centres at the maximum and possible level of service. Therefore it is very important to maintain these roads as they are subjected to heavy traffic and on monsoon or poor drainage conditions which may damage the pavements at a faster rate further requiring timely maintenance and costly rehabilitation. Assessing the condition of the pavement periodically is important so that maintenance work can be taken up accordingly in order to slow down the deterioration rate. A tool which can access the deterioration of pavement is a Pavement Condition Index (PCI) which is a distress study carried out on pavement. PCI is a numerical rating of the pavement condition that ranges from $0-100$ with 0 being worst possible condition 100 being the best possible condition. Therefore, this paper aims at bringing out the methodology used in carrying out the survey on the pavement and for rating of the pavement (PCI) with the case studies of four arterial roads of Rajarajeshwari Zone, Bangalore city and the PCIs of rating of these pavements at the time of studies was found to be from very poor to excellent. Pavement management strategies have been proposed based on the condition rating.
\end{abstract}

Keywords: Flexible Pavements, ASTM, PCI, Pavement Maintenance, Arterial roads $* * *$

\section{INTRODUCTION}

Road maintenance is one of the important components of the entire road system. The maintenance operations involve the assessment of road condition, diagnosis of the problem and adopting the most appropriate maintenance steps. Even if the highway is well designed and constructed, they require maintenance, the extent of which will depend on several factors including the pavement type. In order to carry out design of pavement rehabilitation, the existing pavement condition must be evaluated. Such an evaluation usually involves the assessment of the existing pavement surface distress, roughness, rutting.

During the past four decades, Bangalore has seen many developments in the form of increased land use of urban and rural areas, rapid growth of population and increasing number of motorised and non-motorised vehicles, with steep rise in industrial, commercial, and residential activities improved transport system namely, Bangalore Metro which is under progress. Therefore it is very important to maintain these roads as they are subjected to heavy traffic (truck load) and on monsoon or poor drainage conditions which may damage the pavements.

\subsection{Need for the Study}

For the improvement of urban road condition, there is a need to develop a set of procedures that will provide a systematic evaluation of highway needs, based on appropriate engineering decision and expert knowledge and at the same time to determine which road stretches need maintenance and which are the sections for which the maintenance operation can be deferred.

\subsection{Objectives of Present Paper}

The objectives of the present paper is to,

1. Identify the arterial road length in the selected zone,

2. To assess the condition of selected stretches based on distress survey,

3. To evaluate the PCI value of different sections of road,

4. To recommend the pavement management strategies based on PCI values

\section{REVIEW OF LITERATURE}

\subsection{General}

In the stream of roadway technology, pavement distress and failure is considered as a complex as several factors are 
responsible for the pavement deterioration and failure. The type and extent of maintenance requirement for a road also depends on the serviceability standard laid down, the maintenance needs, funds available and many other factors. The current engineering practice for selection of maintenance and rehabilitation alternatives is based on subjective judgment and engineering experience.

\subsection{Pavement Condition Index (PCI)}

Initially PCI was developed by the United States Army Corps of Engineers and is based on a visual survey of the pavement [1]. PCI is a numerical rating of the pavement condition that ranges from $0-100$ with 0 being worst possible condition 100 being the best possible condition [2]. It is a statistical measure and requires manual survey of the pavement. PCI surveying processes and calculation methods have been standardized by ASTM for both roads and airport pavements.

The PCI provides a measure of the present condition of the pavement based on the distress observed on the surface of the pavement, which also indicates the structural integrity and surface operational condition (localized roughness and safety). The PCI cannot measure structural capacity nor does it provide direct measurement of skid resistance or roughness. It provides an objective and rational basis for determining maintenance and repair needs and priorities. Continuous monitoring of the PCI is used to establish the rate of pavement deterioration, which permits early identification of major rehabilitation needs. The PCI provides feedback on pavement performance for validation or improvement of current pavement design and maintenance procedures.

The PCI values obtained from visual inspection i.e. distress survey by recording the severity and extent of the various distress namely cracking, rutting and potholes occurred to pavement can be utilized well in prioritizing the maintenance strategies [3]. This method provides cost effective maintenance and rehabilitation measures for planners and decision makers for maintenance of pavement in road network.

The PCI provides an objective rational basis for determining the maintenance and rehabilitation needs of highway pavements and for prioritisation of the pavement sections for maintenance on priority. This methodology considers the common type of distresses in highway pavements and suggests the maintenance treatment considering the overall health of the pavement section [4]. PCI is meant to provide an objective, rational basis for determining maintenance and rehabilitation needs and priorities and a warning system for early identification or projection of major repair requirements or both.

The PCI can be used as a tool for assessing the condition of the pavement for periodic maintenance work which could be taken up accordingly in order to slow down the deterioration rate of rural roads constructed under PMGSY scheme in India [5].

The cost effective maintenance and management strategies can be developed by assessing the severity and extent of measured pavement distress values, further which can be used as input to Pavement Maintenance \& Management System (PMMS). In developing the maintenance and management strategies PCI plays a major role including type of pavement and other road related information [6].

\section{FIELD STUDIES \& DATA COLLECTION}

\subsection{General}

The methodology adopted in this study provides a simple approach in the development of PCI for the selected arterial road stretches in Bangalore city for taking up cost effective maintenance measures/treatments. The maintenance treatment recommendations are based on PCI which involve the collection and preparation of road inventory data and report, visual distress survey of the selected stretches based on pavement performance related parameters.

\subsection{Surface Distress Measurements}

The existing pavement condition initially was assessed by visual inspection of the selected road stretches, and then the sections were made based on the distress type and severity. Then pavement surface distress measurement was carried out involving the identification of both type and severity of the pavement distresses present in the study area of the road sections. This procedure was performed with the use of Unified Facilities Criteria (UFC)-2004, ASTM D 6433-07, Paver asphalt distress manual-1997, Distress Identification Manual FHWA USDOT-2003, Oregon DOT Manual-2010 and SHRP-P-338 which contains definitions and information concerning pavement distresses.

\subsection{Study Stretches}

The following four arterial roads in Rajarajeshwari Zone, Bangalore city with total length of $36.5 \mathrm{~km}$ were selected and the same with brief inventory detail is listed in Table 1. All the roads selected are within the Bruhat Bangalore Mahanagara Palike (BBMP) limits. 
Table 1 Selected Road Stretches

\begin{tabular}{|l|l|l|l|l|l|l|}
\hline $\begin{array}{l}\text { Location } \\
\text { Code }\end{array}$ & Road Name & $\begin{array}{l}\text { Length } \\
\text { in km }\end{array}$ & $\begin{array}{l}\text { Pavement } \\
\text { Type }\end{array}$ & $\begin{array}{l}\text { Divided } \\
\text { Carriageway }\end{array}$ & $\begin{array}{l}\text { Width } \\
\text { in mtr }\end{array}$ & $\begin{array}{l}\text { No. of } \\
\text { Sections } \\
\text { made }\end{array}$ \\
\hline 1 & Magadi Road & 9.5 & Flexible & Yes & 15 & 5 \\
\hline 2 & Uttarahalli Road & 17 & Flexible & No & 10 & 9 \\
\hline 3 & $\begin{array}{l}\text { Subramanyapura } \\
\text { Vasantapura Main } \\
\text { Road }\end{array}$ & 3.7 & Flexible & No & 10 & 2 \\
\hline 4 & Muddinapalya Road & 6.3 & Flexible & No & 10 & 4 \\
\hline
\end{tabular}

\subsection{Methodology of Data Collection}

Bangalore is India's fifth-most populous urban agglomeration, growing metropolitan city with population more than 8.426 million. The local authority (BBMP) has divided Bangalore into 8 zones namely, Bommonahalli Zone, Bangalore East Zone, Bangalore South Zone, Byatarayanapura, Mahadevapura, Bangalore West Zone, Dasarahalli and Raja Rajeshwari Nagar Zone. For the present study RR zone (details shown in Table 2) is chosen as this zone covers major roads that connects many educational institutions, hospitals, malls, toll roads, religious places, ring roads, developing areas and it also consist a major connectivity to another growing city Mysore. The roads in this zone considerably subjected to heavy axle loads, on monsoon rain and many developments work namely Bangalore Metro (Namma Metro) due to which the roads constructed are failed to serve their intended function, hence a study in this view is required.

Table 2 Road network detail of Rajarajeshwari Zone

\begin{tabular}{|l|l|}
\hline Category of the road & Length in $\mathrm{km}$ \\
\hline Arterial & 94 \\
\hline Sub Arterial & 118 \\
\hline Collector street & --- \\
\hline Local Street & --- \\
\hline Total Length & 212 \\
\hline
\end{tabular}

There are many feasible approaches to defining performance and assessing the condition of road facilities. A pavement condition needs to be characterized in quantifiable terms so that the potential performance can be associated to a defined condition. In this study (walk through) pavement survey was conducted and in this regard the procedure adopted was based on visual assessment of the type, quantity and severity of pavement distresses and results in the PCI. UFC - 2004 [1] was referred for calculation of PCI, the detail calculation procedure is explained in further section. It was aimed towards the evaluation and analyzing the existing roadway conditions so that a realistic definition of the individual problems and structural requirements of the roadway can be made.

\section{ANALYSIS \& RESULTS}

\subsection{Determination of Deduct Values and Pavement Condition Index}

A Deduct Value (DV) is defined as the value that represents the amount of distress that a pavement has undergone or is subjected to. Each section was inspected and distress data, severity levels such as Low (L), Medium (M) and High (H) were recorded in the distress survey data sheet. The density of each individual distress was calculated using the Eqns. 1, 2, 3.

$$
\begin{aligned}
& \text { Density }=\frac{\text { Distress amount in square meters }}{\text { Sample area in square meters }} \times 100 \% \\
& \text { Density }=\frac{\text { Distress amount in linear meter }}{\text { Sample area in square meters }} \times 100 \% \\
& \text { Density }=\frac{\text { Number of potholes }}{\text { Sample area in square meters }} \times 100 \%
\end{aligned}
$$

Then the DVs were determined from the DV curves, then for each distress type and severity Total Deduct Value (TDV) was computed by summing up all the individual DVs then the Corrected Deduct Value (CDV) was determined from CDV curve shown in Fig. 1. Then the PCI was computed using the Eqn. 4. All the PCIs and rating for the respective section with TDV and CDV are presented in Table 3.

$$
\mathrm{PCI}=100-\mathrm{CDV}
$$




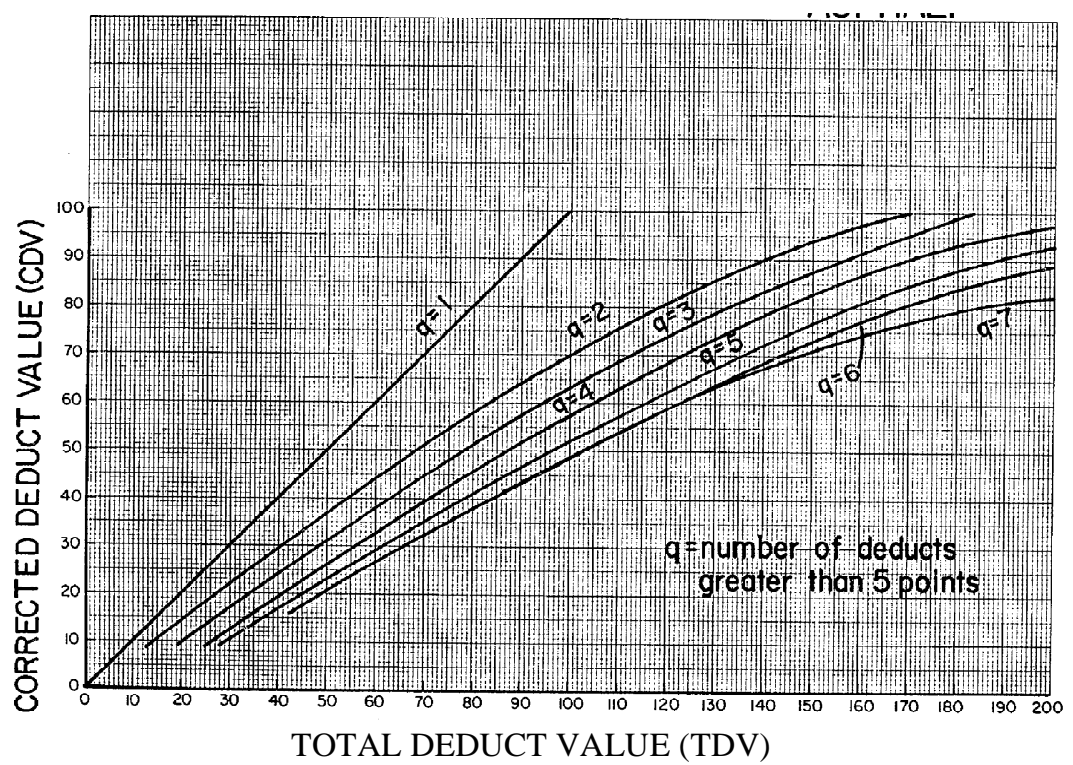

Fig1. Corrected deduct value curves for asphalt-surfaced pavements

Table 3 Computation of Pavement Condition Index

\begin{tabular}{|c|c|c|c|c|c|c|c|c|}
\hline $\begin{array}{l}\text { Location } \\
\text { code }\end{array}$ & Beginning Post & End Post & $\begin{array}{l}\text { Length of } \\
\text { the } \\
\text { Section in } \\
\mathrm{km}\end{array}$ & $\begin{array}{l}\text { Width } \\
\text { of the } \\
\text { Section } \\
\text { in } m\end{array}$ & TDV & $\mathrm{CDV}$ & PCI & RATING \\
\hline \multirow{10}{*}{1} & Magadi Road Toll Booth & Mahadeshwara Nagar & 2.7 & 8 & 63 & 40 & 60 & Good \\
\hline & Mahadeshwara Nagar & $\begin{array}{lcc}\begin{array}{l}\text { Magadi } \\
\text { Booth }\end{array} & \text { Road } & \text { Toll } \\
\end{array}$ & 2.7 & 8 & 38 & 28 & 72 & Very Good \\
\hline & Mahadeshwara nagar & Sumanahalli Bridge & 2.7 & 7.5 & 86 & 55 & 45 & Fair \\
\hline & Sumanahalli Bridge & Mahadeshwara Nagar & 2.7 & 7.5 & 107 & 62 & 38 & Poor \\
\hline & Sumanahalli Bridge & Kamakshipalya & 2.4 & 7.5 & 140 & 73 & 27 & Poor \\
\hline & Kamakshipalya & Sumanahalli Bridge & 2.4 & 7.5 & 143 & 80 & 20 & Very Poor \\
\hline & Kamakshipalya & Veeresh Theatre & 1.2 & 7.5 & 100 & 58 & 42 & Fair \\
\hline & Veeresh Theatre & Kamakshipalya & 1.2 & 7.5 & 136 & 70 & 30 & Poor \\
\hline & Veeresh Theatre & $\begin{array}{lll}\begin{array}{l}\text { Chord } \\
\text { Bunk) }\end{array} & \text { Road } & \text { (Petrol } \\
\end{array}$ & 0.5 & 7.5 & 101 & 57 & 43 & Fair \\
\hline & $\begin{array}{lll}\text { Chord } & \text { Road } & \text { (Petrol } \\
\text { Bunk) } & & \\
\end{array}$ & Veeresh Theatre & 0.5 & 7.5 & 85 & 54 & 46 & Fair \\
\hline \multirow{7}{*}{2} & $\begin{array}{l}\text { SJBIT College of } \\
\text { Engineering. }\end{array}$ & $\begin{array}{l}\text { Kengeri sat. Bus Stop @ } \\
\text { Mysore Road }\end{array}$ & 2.2 & 10 & 100 & 63 & 37 & Poor \\
\hline & $\begin{array}{ll}\text { JSS College } & \text { of } \\
\text { Engineering } & \end{array}$ & $\begin{array}{l}\text { SJBIT College of } \\
\text { Engineering. }\end{array}$ & 1.2 & 10 & 56 & 35 & 65 & Good \\
\hline & Pattalamma Temple & $\begin{array}{l}\text { JSS college of } \\
\text { Engineering }\end{array}$ & 2.7 & 10 & 101 & 57 & 43 & Fair \\
\hline & Uttaralli Main Cross & Pattalamma Temple & 2 & 10 & 97 & 56 & 44 & Fair \\
\hline & Chikkalasandra Cross & Uttarahalli Circle & 2.8 & 7.5 & 10.5 & 11 & 89 & Excellent \\
\hline & Kadrenahalli & Chikkalasandra Cross & 2 & 7.5 & 52 & 38 & 62 & Good \\
\hline & $\begin{array}{l}\text { ORR Near } \text { Dayanand } \\
\text { Sagar College }\end{array}$ & Banashankari BMTC & 1.4 & 12 & 66 & 43 & 57 & Good \\
\hline
\end{tabular}




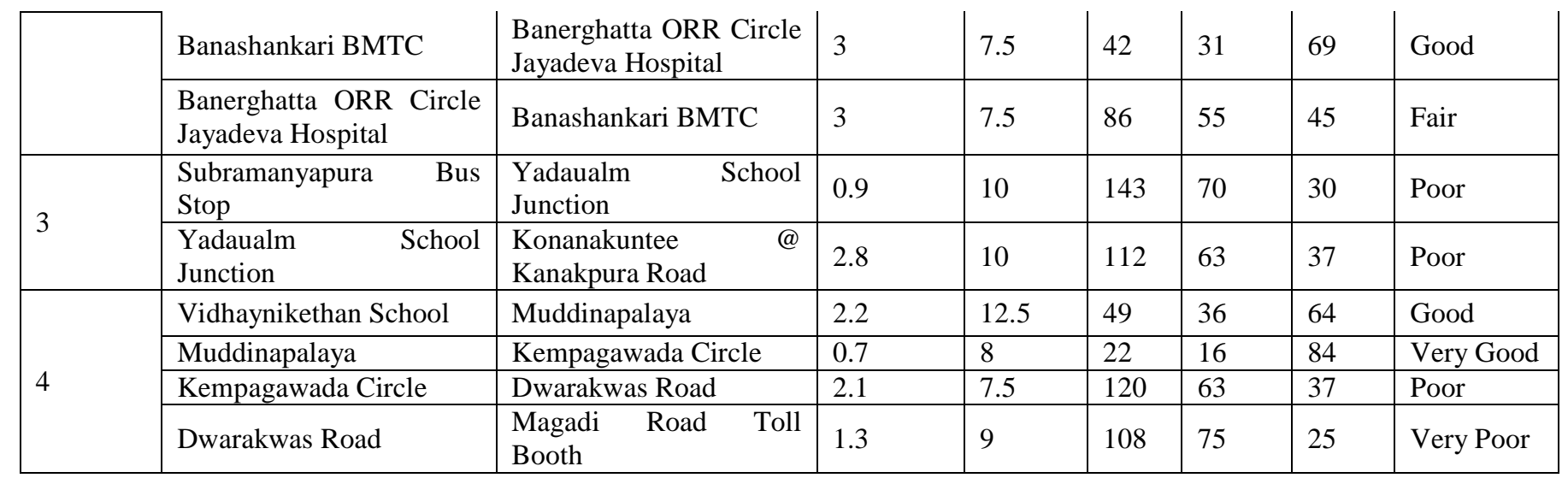

Determination of appropriate maintenance measures

\begin{tabular}{|l|l|l|}
\hline PCI Range & Rating & Maintenance Measures \\
\hline $86-100$ & Excellent & No maintenance required \\
\hline $71-85$ & Very Good & Little or no maintenance \\
\hline $56-70$ & Good & Routine maintenance, crack sealing and minor patching \\
\hline $41-55$ & Fairs & $\begin{array}{l}\text { Preservative treatments (seal coating or thin non- } \\
\text { structural overlay 2" or more) }\end{array}$ \\
\hline $26-40$ & Poor & $\begin{array}{l}\text { Needs patching and repair prior to major overlay Milling } \\
\text { and removal of deterioration extends the life of overlay. }\end{array}$ \\
\hline $11-25$ & Very Poor & Needs reconstruction with extensive base repair. \\
\hline $0-10$ & Failed & Total Reconstruction \\
\hline
\end{tabular}

\section{DISCUSSION \& CONCLUSIONS}

1. PCI provides an objective rational basis for determining the maintenance and rehabilitation needs of urban roads.

2. The suggested methodology considered the common type of distresses in urban roads and suggests maintenance treatments considering the overall health of the pavement.

3. The urban sections that possess higher value of pavement condition index do not require maintenance and pavement section that are assigned lower value of pavement condition index require maintenance on priority.

4. PCI serves as a warning system for early identification or projection of major repairs required.

5. Potholes, weathering and raveling, alligator cracking, polished aggregate and rutting were the major distress identified on urban stretches. In some parts of the selected section of roads there were no pavement or wearing course was absent which require immediate attention.
6. Due to cutting of pavements across and along the roads for providing service lines or for repairing existing service lines and subsequent improper resurfacing has resulted in deterioration of pavements.

7. PCI is a function of the type of distress, density of distress and severity of distress hence management strategies have been recommended based on PCI values as per PASCER manual

\section{REFERENCES}

[1] US Army Corps of Engineers, "PAVER asphalt distress manual" Technical report TR97/104, (1997).

[2] ASTM D 6433-07, "Standard Practice for Roads and Parking Lots Pavement Condition Index Surveys", (2007).

[3] L. Udayakumar, R. Vivan Robert and M. S. Amarnath, "Ranking Technique for Prioritisation of Arterial and Sub Arterial Roads for Maintenance Management", Journal of Indian Highways, Vol. 36, No.11, (2008) pp. 41-51 
[4] N H Suma, Nirmalya Chakraborty and A Veeraragavan, "Simplified Methodology for Prioritisation of Pavement Maintenance Based on Pavement Condition Index", $4^{\text {th }}$ International Conference on Managing Pavements, (1998).

[5] Ryntathiang and Teiborland Lyngdoh, "Pavement condition index as a tool for assessing the rural road pavements: a case study of the Assam rural roads", Journal of Indian Highways, Vol. 39, No.10, (2011) pp. 41-57.

[6] Saad Issa Sarsam, "Development of Pavement Maintenance Management System Using Visual Evaluation of Asphalt Concrete Surface Condition and Expert System", $7^{\text {th }}$ International Conference on Managing Pavement Assets, (2008). 